\title{
Research
}

\section{Sharing control of appointment length with patients in general practice:}

\author{
a qualitative study
}

\begin{abstract}
Background

There is little published research into the impact, on both doctor and patient, of handing over responsibility for choosing appointment length to the patient.
\end{abstract}

\section{Aim}

To investigate what impact giving patients control of their appointment length has on the patient and doctor experience.

\section{Design and setting}

A qualitative study in a single medical practice in Inverness, Scotland.

\section{Method}

Eligible patients making a 'routine' appointment were given a choice of appointment length $(5$ 10,15 , or 20 minutes). After the consultation, patients were invited to take part in a focused interview. Doctors were asked to keep an audio diary and their experience was explored further in a facilitated focus group. Data were analysed using a thematic analysis approach.

\section{Results}

Key themes that emerged for patients included the impact of the shift in power and the impact of introducing the issue of time. For doctors, important themes that emerged were impacts on the provider, on the doctor-patient relationship, and on the consultation.

\section{Conclusion}

Giving patients greater responsibility for choosing appointment length may improve the experience for both doctors and patients.

\section{Keywords}

appointment length; consultation; control; general practice; patient choice; responsibility.

\section{INTRODUCTION}

General practice consultations have become of greater duration and complexity than in previous times; ${ }^{1}$ in the UK an average consultation lasted for 11.7 minutes in 2006-2007, compared with 8.4 minutes in 1992. ${ }^{2}$ The general medical services (GMS) contract and patients with multiple comorbidities are influences. ${ }^{3}$ Longer consultations can be associated with improved quality of care and increased patient enablement; ${ }^{4}$ a recent editorial, published in the BJGP, questioned the appropriateness of 10-minute consultations, with a call for 'reflection, innovation, and new research into the lengths of consultations provided to patients'.

In a 1986 lecture, Metcalfe captured the fundamental importance of the general practice consultation:

If we as GPS are to make our unique contribution, it will be as personal doctors, whose way of listening, examining, diagnosing, advising, treating, and monitoring has as its objective not only the cure or control of disease, but the protection or expansion of our patients stature, autonomy, and personal space. That is the kind of health we can deliver, even to people with disease, even to people who are dying. We do it in the consultation.'

R Sampson, FRCGP, GP; J O'Rourke, FRCGP, GP and assistant director of Postgraduate General Practice Education, North of Scotland; A Thain, FRCGP, GP; R MacVicar, FRCGP, GP, and director of Postgraduate General Practice Education, North of Scotland, Cairn Medical Practice, Inverness. D Heaney, MA(Hons), senior research fellow, Centre for Rural Health, University of Aberdeen, Inverness. S Holden, BSc, research coordinator for primary care, NHS Highland Research and Development Department, Centre for Health Science, Inverness. R Hendry, medical student, School of Medicine and Dentistry,
There is a distinct body of literature on the consultation in general practice ${ }^{7-13}$ offering a bewildering menu of theoretical models. Although patients can estimate how long they need for a consultation, ${ }^{14}$ little attention has been paid to the possibility of giving control of the choice of appointment length to the patient. The study, therefore, set out to explore the effect on both the doctor and the patient of 'handing over' the choice of booked appointment length.

\section{METHOD}

The study was conducted in a single NHS general practice; Cairn Medical Practice is a largely urban practice in Inverness, Scotland, with a patient population totalling 9700. To participate patients had to fulfil certain criteria (Box 1). Those patients who were eligible and wished to make a routine appointment were invited, at the time of booking, to choose a slot lasting 5-, 10-, 15-, or 20 minutes. Those not wishing to take part were offered a standard appointment (10 minutes) with the same doctor. Variable-length appointments were available in a single daily 'research surgery' running between 12 December 2011 and 20 January 2012.

On arrival at the practice for their booked appointment, patients were provided with a participant information sheet lavailable from the authors on request) and were
University of Aberdeen, Aberdeen Address for correspondence Rod Sampson, Cairn Medical Practice, 15 Culduthel Road, Inverness, IV2 4AG. E-mail: rod.sampsonanhs.net Submitted: 28 June 2012; Editor's response: 17 July 2012; final acceptance: 29 August 2012. (CBritish Journal of General Practice

This is the full-length article (published online 25 Feb 2013) of an abridged version published in print. Cite this article as: Br J Gen Pract 2013; DOI: 10.3399/bjgp13X664234 


\section{How this fits in}

Choice is an important issue for patients and they can usually assess accurately how long a consultation they need. This study describes some benefit for both the patient and the doctor of giving patients responsibility for choosing their appointment length. Both patients and doctors perceived greater patient responsibility for time management within the consultation, allowing patients to plan their consultations better. Preconsultation activation of guiding patients in how to express their ideas, linked to patient choice in consultation times, may improve the experience of consultations for both doctors and patients.

taken through the process of consent. At this stage, they were invited to take part in an interview after their consultation. Patients were interviewed using a semistructured approach (Box 2). If at any point during this consent process they withdrew, they kept their booked appointment.

Doctors were asked to keep an audio diary at the end of each research surgery. This was to include answers to the following two questions:

- Did giving patients a choice of appointment length impact on surgery and, if so, how?

- What feelings did giving patients choice of appointment length generate in you?

The first question aimed to ascertain the impact on process, while the second was to determine the impact on the individual.

Doctors' experiences were also evaluated by a focus-group discussion, which was audiorecorded and facilitated by an experienced healthcare researcher. The

\section{Box 1. Inclusion criteria}

- Aged $\geq 16$ years

- Booking an appointment for oneself, either by telephone or face-to-face at the reception desk

- Booking a routine appointment with a partner at Cairn Medical Practice

- Capacity to make decisions

- Good understanding of written and spoken English, not requiring an interpreter to understand the details of the study or to complete the paperwork required

'Routine' refers to an appointment, which is neither an 'on-the-day' request nor a request for a 'double appointment' (20 minutes), and which is a non-special appointment, for example, minor surgery. ${ }^{b}$ NonEnglish speakers/subjects unable to read and write English were excluded due to the time constraints involved in the study. There was insufficient time available to organise interpreters specifically for the study and insufficient funds available to produce translated study materials. It was not anticipated that this would result in significant numbers of subjects being excluded by these criteria. This also enabled a first-hand account from the patient to be included. audio recordings were transcribed and stored on the NHS secure practice server, accessible only to the research team. All clinical participants were practice partners, none were trainees or medical students. The partnership group was mixed in terms of age, sex, and sessional commitment.

\section{Data analysis}

Data were analysed using a thematic analysis approach using NVivo 9.2 software. Transcripts of the patient interviews were analysed using the steps outlined by Braun and Clarke. ${ }^{15}$ Each interview was placed into one of four categories by the researcher, based on a subjective assessment of the depth and richness of the patient experience described. The research team met to read and analyse the interview transcripts deemed to be most rich in terms of descriptions of the patient experience, marking phrases they felt exemplified particular themes. The group then compared individual analyses to build a consensus.

All examples of the same theme from different transcripts were viewed together to check the consistency of the theme. Its attributes were then refined or expanded as necessary. Two researchers then independently analysed the next category of transcripts, highlighting phrases that exemplified the themes already identified, while remaining vigilant for any emerging new themes. Other interview categories were analysed by a single researcher, as it was anticipated that no new themes would emerge.

The transcripts of all the doctors' audio diaries were analysed by the whole research team. The focus-group data were analysed independently by two researchers, then compared and coded.

\section{Confidentiality and data protection}

The strictest standards of confidentiality and data protection were adhered to throughout the study. All original hard copies of sheets that contained participants' identifiable data were stored securely within Cairn Medical Practice. All derived electronic data were stored on the secure, encrypted NHS server at the practice. Patients were identified by a sequentially assigned participant study number; only the master research spreadsheet linked participant study number to surname, date of birth, and Community Health Index number. The only copy of this document remained on the secure practice server.

All the study researchers were either doctors or medical students and were 


\section{Box 2. Participant interview schedule}

Why did you choose the particular length of consultation time with the doctor today?

What effect did choosing the length of appointment have on you?

What difference did choosing the length of appointment have during the consultation or on the outcome?

Can you see any advantages or disadvantages in choosing your appointment length in the future?

Supplementary prompts:

- Personal convenience/reason behind the consultation

Would consultation length matter for all problems or just some?

- What were your hopes for choosing the consultation length? Did this occur? familiar with, and bound by, the regulations surrounding patient confidentiality.

\section{RESULTS}

A total of 174 patients were recruited to the study, with 56 of these agreeable to, and subsequently completing, a followup interview. There were no statistically significant differences in terms of age or sex between those who were, and those who were not, agreeable to interview. A summary of the main themes generated from patient interviews and the doctors diaries and focus-group discussion are outlined in Box 3.

\section{Impact of shift in power}

Choice of appointment length shifted power, which provided benefits and risks for patients. Some patients were better able to plan their consultation and reported an improved consultation experience; some felt they could help ensure they didn't use too much of the doctor's time:

And I thought if you know the length of time you've got, it's a good idea so you can gauge how much time you've got with the doctor. You're not going to be in there over your time. You know exactly how long you've got to explain to the doctor your problem. (P 163)

Some patients reported increased confidence, reduced anxiety, and greater empowerment:

... because I was prepared, I knew exactly what I wanted to say.' (P 92)

I can see where also it might make you feel more empowered because there was an element of you controlling the length of time and ... perhaps [for] some people who will feel quite anxious going to the doctor, it might help.' (P 85)

Other patients were concerned they would negatively affect the doctor's time. Part of this concern was linked to some negative perceptions of the appropriateness of other patients' presentations and motivations:

'There are people out there that, to see the doctor, that's someone to socialise with that day, and someone to tell all their woes to. A doctor isn't a social worker; you've got to think of all the patients, not just the one that wants a chat.' (P 35)

Concerns were also raised by patients about how well some patients could accurately choose appointment length:

If you get somebody, an older person, that maybe doesn't want to trouble the doctor; you might find that they would take too short an appointment.'(P 71)

\section{Impact of introducing the issue of time}

There were direct positive effects within the consultation, including it having a more comfortable pace from a patient perspective:

I was aware of time ... you're not always aware of time when you're with a doctor. (P 162)

A greater awareness of appointment length led to improved time efficiency for the doctor, and possibly, therefore, also for other patients:

... there was time for not feeling that, by introducing other questions, I was making the schedule run late. So it gave me the opportunity to ask all the questions I wanted to.' (P 71)

\section{Impact on the provider}

There were both positive and negative impacts on the doctor; some felt more at ease, while others experienced significant personal anxiety sufficient to cause both mental and physical effects:

Initially when I had actually looked at my list of patients yesterday, before coming in to work today, I was absolutely worried about the fact that it was too much to see so many patients who had booked 5-minute appointments. I was dreading coming in this morning. I didn't get a good night's sleep last night because I knew I would have to leave fairly early from the practice and do some examining of students in the afternoon. So I was really worried in case everything went very pear-shaped and I was running behind, stressed, running 


\section{Box 3. Themes identified by patients and doctors}

\begin{tabular}{ll} 
Theme & Impact \\
\hline Patients & - Improved planning for the consultation \\
Shift in power & - Improved consultation experience \\
& - Risks of having control of appointment length \\
\hline Introducing the issue of time & - Awareness of time as an important commodity \\
\hline Doctors & - Impact on the doctor \\
Impact on provider & - Impact on the practice staff \\
\hline Impact on relationship & - Doctors' perceptions of patient experience \\
& - Mismatched expectations \\
\hline Impact on the consultation & - Challenging doctors preconceptions \\
\hline
\end{tabular}

on adrenaline, not really doing the right thing by people ... that was putting a lot of pressure on me to try and really stick to the times so that I wouldn't feel like I was getting too far behind.' (GP 2)

Doctors' feelings appeared to be influenced by their perception of how well the patient was able to choose their appointment length. One doctor expressed concern that, if patients had not accurately estimated appointment length, this could affect how well the doctor was able to manage the patient. Interestingly, those doctors that experienced less anxiety felt that patients were more accurately able to estimate the appointment length they required. There was a sense from several doctors that patients seemed to be more empowered; one doctor described a more equal relationship as a result:

I felt the patient was more empowered. I felt less rushed and more relaxed. I enjoyed the surgery more. I felt on a more equal footing with the patient because they had had some choice in their appointment time. If the patient requested a 15-minute appointment and they had come in with something that was not so time consuming, it made me wonder if there was something else they were hoping to address when they had asked for longer. This did not seem to be the case.' (GP 5)

Doctors involved in the process commented on the impact of the intervention on practice staff:

Lots of things going on that looked like it was probably an added pressure and it felt like there was absolutely a real buzz up here among the clinicians, but Im not sure I was aware of the same buzz with the admin and management.'(GP 3)

\section{Impact on the relationship}

Doctors described experiences that were relevant to the doctor-patient relationship. Overall, their perception was that patients were more empowered, were better able to express themselves, and had greater ownership of the consultation. They were more considered with respect to the content of the consultation, and were less anxious within it:

I think I felt the patients felt the appointment was much more theirs, and that they were more empowered, and that they had given [everything] a bit more thought because they had had to choose a time as to what they were going to use the time for.' (GP 5)

Strong emotions were expressed about mismatched expectations. The expectation from some doctors was that, if given the choice of appointment length, patients would need to choose accurately on the basis of the number and depth of problems presented, while recognising the limitations of what can be achieved in a time-limited consultation. One doctor saw the intervention as being useful in this regard; it could give the patient greater awareness of time, potentially reducing the level of mismatched expectations:

Il like the sense of giving them the choice and I think it empowers them. And it also definitely makes me feel more relaxed, but I could easily see if you have got somebody booking a 5-minute appointment and then wanting to bring a list in, I would feel quite angry and annoyed about that.' (GP 9)

Some doctors were surprised by how accurately patients could choose their appointment length. Despite this, one doctor thought that, if the intervention was to continue as part of normal practice, patient education would be required:

I had worried that I might have to inform patients they had made a choice and we should cut the surgery at that point but this never felt required or appropriate... I think with appropriate patient education this would be a very positive move forward to allow patients to select their own appointment length.' (GP 3)

Impact on the consultation

Doctors described their consultations as 
being improved directly because of the intervention. It would seem that, in some cases, allowing patients to choose their appointment length left sufficient space in the consultation for the doctor to undertake health-promotion activities:

'The "luxury" that this provided allowed me to consolidate smoking-cessation messages that she had had before, to congratulate her for being off the cigarettes for 5 days and to plan for how to stay abstinent. From the perspective of my chair, this was a very positive consultation, potentially, with significant impact on the patient's future health.' (GP 6)

In one case, the sharing of ownership of the consultation led to a greater sense of shared agreement with the patient, which led to greater doctor satisfaction with regard to their role:

I felt I had done a better job and actually ended somebody's very difficult consultation without a fight, and actually ended the consultation with some sense of shared agreement. Maybe not complete, but not the kind of "I've got to go now, I've got to see other patients, your time's up"... it was very powerful.' (GP 7)

Doctors also perceived that patients were taking greater responsibility for the time management of the consultation:

'The positive impact on the surgery was, interestingly, I had a couple of patients who were very aware that they had requested a certain appointment length lusually 10 minutes) and were veryanxious not to run over. So it was interesting to see the patient feeling the pressure of the appointment time, rather than the doctor.' (GP 3)

This led to the earlier closure of a consultation for one doctor, which previously had generally overrun. One doctor noticed that patients also seemed to be limiting the number of problems presented, based on the appointment length they had chosen. There was a subtle impression that more complex patients were appropriately (from the doctors' perspectives) choosing longer appointment lengths. The sharing of ownership of time also led to shared expectations:

It was a really pleasant surgery today and it was almost as if both patient and doctor kind of knew what was expected of them. (GP 9)

\section{DISCUSSION}

Summary

Both doctors and patients described a greater perceived sense of patient empowerment in handing over the freedom to choose appointment length. This shift in power was largely welcomed, with doctors describing a more balanced relationship and patients feeling more confident and better able to manage their consultation. The sharing of power, however, was not universally welcome; for some patients there was anxiety over whether this would have a negative impact on the doctor's time and a concern about how some of their fellow patients might misuse the freedom to choose appointment length.

Doctors and patients shared a concern about the accuracy with which patients could choose their appointment length. However for many doctors, this perception was challenged when they experienced surgeries in which patients had clearly chosen appropriately.

An interesting perception from some doctors was that, as a result of handing over responsibility for choosing appointment length, patients also seemed to take greater responsibility for time management within the consultation. This was echoed by comments from some patients; their greater awareness of time led to the perception of greater patient efficiency to benefit the doctor and other patients, and allowed them (the patients) to plan their consultations better.

\section{Strengths and limitations}

Little work has been done to investigate the impact on both doctors and patients of giving patients the responsibility for choosing the length of time for their appointments. Investigating both doctor and patient perspectives provided richness to the data that would not have been evident if only one of these groups had been examined in isolation. However, there are several potential limitations of the study. The research was carried out in a single practice and conducted by researchers who were also the GPs of the participating patients. As a result, there is potential for researcher bias and for patients to provide what they may have felt to be the 'right answers'. In an attempt to counter this, the patient interviews were carried out by a research assistant unknown to participants.

The numbers involved are substantial from a qualitative research perspective and the themes that have arisen are likely to be widely relevant. 


\section{Comparison with existing literature}

The concept of choice is important for patients $^{16}$ and they value being involved in decision making. ${ }^{17}$ Bodenheimer ${ }^{18}$ describes the 'pre-activation' of patients before their consultation la process of assisting patients to be more assertive during their visit to the doctor). The studies cited by Bodenheimer encouraged patients to consider the content of their consultation before it began. Use of previsit training booklets improved patient information seeking, patient retention of information post-consultation, compliance with medications, and improved healthrelated behaviour change. 19,20 Likewise, meeting with a health educator prior to their consultation had a measurable clinical outcome la statistically significant decrease in $\mathrm{HbA1c}$ ) in patients with diabetes. ${ }^{21}$

It is already known that interventions encouraging patients to consider their own agenda prior to consulting can not only improve the volume of problems identified within the consultation, but also increase patient satisfaction with the depth of the doctor-patient relationship. ${ }^{22}$ Pre-consultation 'activation' can also increase both patient satisfaction and their perceptions of communication. ${ }^{23}$ The simple intervention in the study lgiving patients control over the allotted time for their appointment) caused patients to think about their consultation ahead of time, and work out what they wanted to achieve and how long it might take to do so; this may, therefore, have had a similar preactivation' effect to the one described by Bodenheimer. ${ }^{18}$

Tuckett et a ${ }^{24}$ indicated that consultations should be seen as 'meetings between experts'. By specifically ensuring that the sharing of ideas occurs, doctors break down the stereotypical model of doctors as experts and patients as individuals with little knowledge or feelings about their problems. This respect for a patient's view is extended in the study by specifically respecting the patient's capacity to choose the length of time they require with the doctor.

Anxiety was expressed by both doctors and patients with regard to the patient's ability to accurately determine the appointment length that would be required. Some doctors in the study were surprised by how well some patients could accurately determine how much time they needed; this finding has been borne out by previous research. ${ }^{14,17}$

Soft evidence from the study's themes have suggested that more complex patients may be able to appropriately choose longer appointment lengths (more than 10 minutes). The study is aware that, in these longer consultations, more psychosocial problems are recognised and more longterm problems are dealt with. ${ }^{4}$ Having to deal with both the demands of the GMS contract and patients with multiple comorbidities may also influence the need for longer consultations. ${ }^{3}$

\section{Implications for practice}

The results of this study suggest that there may be benefits to giving patients greater responsibility for choosing the length of time for their appointments. In doing so, it is important to be aware that this may not meet all the needs of doctors or patients. Educating doctors, reception staff, and patients in how to best use such a system, for the benefit of both doctors and patients would seem necessary.

A quantitative analysis of patient enablement may help further explore the impact of having some degree of control over choice of appointment length.

Further study in the same practice, or in a group of practices, could examine feasibility and operation over a longer period, giving time for potential problems to emerge. Future research could also investigate the impact of the intervention on outcomes such as resource use, workload (for example, in terms of effect on rate of reconsultation), and longer-term satisfaction levels of clinicians, administrative staff, and patients.

Extending Tuckett et al's theme of sharing ideas, ${ }^{24}$ the preconsultation activation of guiding patients in how to express their ideas, linked to patient choice in consultation times, may help us better understand, and improve, the experience of consultations for both doctors and patients.

We thank the partners, patients and staff o Cairn Medical Practice for their participation; Matthew Macdonald, Gillian Heron, Laura Maclean, Emma Macdonald, Karen Deans and Diane Macnicol for administrative support; and the NHS Highland Research and Development Committee.

\section{Discuss this article}

Contribute and read comments about this article on the Discussion Forum: http://www.rcgp.org.uk/bjgp-discuss 


\section{REFERENCES}

1. Freeman G, Horder J, Howie J, et al. Evolving general practice consultation in Britain: issues of length and context. BMJ 2002; 324(7342): 880-882.

2. The Information Centre. GP workload survey. The Information Centre, 2007. http://umw.ic.nhs.uk/pubs/gpworkload laccessed 14 Jan 2013).

3. Department of Health. Delivering investment in general practice-implementing the new GMS contract. London. DoH, 2003.

4. Howie JGR, Porter AMD, Heaney DJ, Hopton JL. Long to short consultation ratio: a proxy measure of quality of care for general practice. Br J Gen Pract 1991; 41(343): 48-54.

5. Silverman J, Kinnersley P. Calling time on the 10-minute consultation. Br J Gen Pract 2012; 62(596): 118-119

6. Metcalfe D. William Pickles Lecture 1986: The crucible. J R Coll Gen Pract 1986; 36(289): 349-354.

7. Balint M. The doctor, his patient and the illness. London: Tavistock Publications, 1957.

8. Byrne PS, Long BEL. Doctors talking to patients. London: HMSO, 1976.

9. Stott $\mathrm{NCH}$, Davis RH. The exceptional potential in each primary care consultation. J R Coll Gen Pract 1979; 29(201): 201-205.

10. Pendleton D, Schofield T, Tate P, Havelock P. The consultation: an approach to learning and teaching. Oxford: Oxford University Press, 1984.

11. Neighbour R. The inner consultation: how to develop an effective and intuitive consulting style. Lancaster: MTP Press, 1987.

12. Stewart M, Brown J, Weston W, et al. Patient-centred medicine: transforming the clinical method. Thousand Oaks, CA: Sage Publications, 1995

13. Silverman J, Kurtz S, Draper J. Skills for communicating with patients. Oxford: Radcliffe Medical Press, 1998.
14. Lowenthal L, Bingham E. Length of consultation: how well do patients choose? J R Coll Gen Pract 1987; 37(304): 498-499.

15. Braun V, Clarke V. Using thematic analysis in psychology. Qualitative research in Psychology 2006; 3(2): 77-101

16. Weir N, Kotecha M, Goel K. Expanding choice options for older patients in relation to practice-based commissioning: a qualitative study of older patients in a small GP surgery. Quality in Primary Care 2007; 15(6): 331-336.

17. Lambourn R. Can patients choose appointment length? Br J Gen Pract 2003; 53(497): 969-970.

18. Bodenheimer T. Helping patients improve their health-related behaviors: what system changes do we need? Dis Manag 2005; 8(5): 319-330.

19. Cegala D, Marinelli T, Post D. The effects of patient communication skills training on compliance. Arch Fam Med 2000; 9(1): 57-64

20. Cegala J, McClure L, Marinelli T, Post D. The effects of communication skills training on patients' participation during medical interviews. Patient Educ Couns 2000; 41(2): 209-222

21. Greenfield S, Kaplan S, Ware J, et al. Patients' participation in medical care: effects on blood sugar control and quality of life in diabetes. J Gen Intern Med 1988; 3(5): 448-457.

22. Middleton JF, McKinley RK, Gillies CL. Effect of patient completed agenda forms and doctors' education about the agenda on the outcome of consultations: randomised controlled trial. BMJ 2006; 332(7552): 1238-1242.

23. Little $P$, Dorward M, Warner $G$, et al. Randomised controlled trial of effect of leaflets to empower patients in consultations in primary care. BMJ 2004; 328(7437): 441 .

24. Tuckett D, Boulton M, Olson C, Williams A. Meetings between experts: an approach to sharing ideas in medical consultations. London: Tavistock; 1985 